\title{
A Synergy-Based Approach through Developing Cross-Disciplinary Module
}

\author{
Tatyana A. Olkhovaya a , Alexander E. Shukhmana, Victoria V. \\ Nevolina $^{\mathrm{b}}$, Lyudmila A. Amirova ${ }^{\mathrm{c}}$ and Natalia A. Zaitseva ${ }^{\mathrm{d}}$
}

aOrenburg State University, RUSSIA; 'Orenburg State Medical University, RUSSIA; 'Bashkir State Pedagogical University named after M. Akmulla, RUSSIA; dPlekhanov Russian University of Economics, RUSSIA.

\begin{abstract}
Considering and overcoming the contradictions occurring while teaching humanities and social sciences was an important stage to understand fully their potential, the leading role of synergetic approach determining current improvements in curricula and teaching methods for implementing new ideas and values, as well as concepts and contents, into various sciences and courses studied by Humanities students. In the course of the research, a concept of 'cross-disciplinary module' has been considered as an innovative model with its pedagogic mechanisms to achieve the synergetic effect, and made it possible to develop its structure and content reasoning. Designing and developing crossdisciplinary modules, as the main technique used in the research, has been developed intentionally to improve teaching and learning Humanities outcomes at university. Theoretical-and-methodological foundation to design and implement them is based on synergy approach principles, related to the goals, structure, content, techniques used to organize and develop the students' knowledge acquisition. The authors believe that the materials proposed may be helpful for the systems of continuing professional education and retraining of pedagogical resources, young scientists and postgraduates, officials and experts managing and controlling educational process.
\end{abstract}

KEYWORDS

Educational module; cross-disciplinary module; synergetic approach; modeling
ARTICLE HISTORY

Received 15 September 2015 Revised 10 November 2015 Accepted 22 February 2016

\section{Introduction}

Aspects of higher education and modern transformation processes in humanities are going beyond conventional academic boundaries of the domestic educational theory and practice. This phenomenon may be explained by the fact that higher education system in Russia, in the conditions of rather fast economic and labour market growth, is acquiring features of an open system with potential for selforganizing and alternative ways of development, and initiation of innovations as

CORRESPONDENCE Tatyana A. Olkhovaya $\square$ tatjana.olhovaja@mail.ru

(c) 2016 Olkhovaya et al. Open Access terms of the Creative Commons Attribution 4.0 International License (http://creativecommons.org/licenses/by/4.0/) apply. The license permits unrestricted use, distribution, and reproduction in any medium, on the condition that users give exact credit to the original author(s) and the source, provide a link to the Creative Commons license, and indicate if they made any changes. 
the elements of synergy. Accordingly, Humanities as a training process is exposed to external impact and begins to respond the environment transformation and subordinate to the synergetic principles of self-organization and self-transformation. Under these circumstances, the requirements of new higher educational standards and labor market, which determine the pedagogic conditions to influence the students' academic outcomes related to Humanities in the form of features and skills declared as necessary, do not fully meet the contemporary educational strategy requirements. This trend is supported by both experimental results in implementing the new standards of higher education and achievements of pedagogics that can be characterized by attempts to find breakthrough solutions. The Russian researchers of the issue (Budanov, 2013; Boguslavskiy, 1999; Vyugina, 2015; Zapesotsky, 2003, Zeer, 2009; Zimnyaya, 2003; Levina et al., 2015) hold an opinion that today's university environment is characterized by elements of synergy that are constituents of the methodological cross-disciplinary principle that is able to display the essence of the multidimensional, multi-component and polyphony processes in teaching Humanities, its openness to co-creativity, self-development, and admitting contingency as a significant factor in development. This principle makes it possible to be ahead in terms of requirements set by the government and labour market, and modifies traditional education process adding self-organization and self-transformation elements, new structure of humanities integration, enriching it with the synergetic ideas, enhanced content and techniques of implementing academic cross-disciplinary modules.

\section{Methodological Framework}

\section{Key concepts}

Theoretical basics of the research are expressed via key concepts (the synergetic approach, self-organization, self-transformation, simulation, an educational module, a cross-disciplinary module, competence, Humanities, labor market).

Synergetic approach is, first of all, the empirical study of systems in transformation. Synergetics is a very broad discipline embracing range of scientific and philosophical studies. Applied to pedagogy it is a theoretical and methodological strategy of introducing the advanced objectives, principles, functions, syllabus, technology of Humanities teaching at university, student self-organizing system capable of reflecting and self-transforming, creating new conditions to boost one's creativity abilities to overcome unilinear nature and dogmatic constraints that open multifunctionality and multidimensionality of the educational theories and hypotheses (Erdyneeva et al., 2016).

Self-organization has been considered in different contexts, so as the result of self-organization in nature can be seen everywhere. It is exhibited through a variety of complex forms, patterns, shapes, and interactions around and within us. For this reason it has no generally accepted meaning, as the abundance of definitions suggests. It's a common knowledge that the system tends to selforganize, in the sense that interactions eventually produce coordination and synergy. In our case it brings to the representation-dependent dynamics of the student as an agent of education through direct and inverse interactions with the environment. The external environment at the given time line is associated 
with the process of Humanities teaching (or learning) focused on self-organizing and self-transforming through the cross-disciplinary educational modules.

A profound change in thinking and awareness leads to self-transformation of the person. The category of self-transformation encompasses intellectual merits that promote personal growth, non-technological methods of enhancing intelligence and rationality. Ideally, education must be responsive to the needs of the times, i.e., for instance, where new challenges arise, there must be constant reformulation and redirection of curriculum theory and practice. Otherwise, education may become an obstacle to society's progress. That's why self-transformation is considered as the highest level of self-organization associated with the improvement and self-development of the systems that can accumulate new experience and use the previous, gained, one.

Modeling is a method of investigating things and phenomena on the basis of their reconstruction, identically reproducing the simulated objects, and providing availability of in-depth and comprehensive study.

An academic module is an independent organizational and methodological structure of an academic discipline representing a complete cycle of educational activities from the stage of presenting an idea to its reflection, accompanied with a system of controls and criteria to determine its effectiveness.

A cross-disciplinary educational module is a system of interaction forms useful for Humanities, Social Sciences and other professionally significant university courses on the basis of the cross-disciplinary communication system of norms, values and invariants of these disciplines; self-organizing and selftransforming to qualitatively new cross-disciplinary units of knowledge through communication. Such a module also is a self-contained course and lasts for given period of time. In our case it covers the cross-disciplinary material according the new upgraded curriculum.

The humanities are academic disciplines that refer to the study of literature, history, language, performing and visual arts or philosophy. A humanity as a system of courses is based on methods that are primarily critical, or speculative, and have a significant historical element, compared to natural sciences that use mainly empirical approaches. According to federal standards of higher education, universities in Russia provide a broad liberal arts education, or humanities, in which all students study the humanities in addition to their specific area of study.

Competencies are the measurable or observable knowledge, skills, abilities, and behaviors critical to successful job performance in future, i.e. the person's ability to use his knowledge, skills and experience in social, cultural, and professional activities in typical and non-typical situations. Competency-Based Education and Training is an approach for teaching and learning concrete skills rather than abstract learning. Learners work on one competency at a time, which is likely a small component of a larger learning goal, and, it's preferable that only once they have mastered it do they move on to others. After that, higher or more complex competencies are learned to a degree of mastery.

A labour market is where workers and employees interact with each other, in an economy it functions with demand and supply of labour, thus reflecting relevant, prospecting and prognostic demands in the human resources in a certain region. 


\section{Research methods}

A set of methods have been applied to achieve the research objectives and solve the tasks. Among them we distinguish the following:

- Theoretical - involve the creation of a theoretical system of analysis based on hypothetical rules, usually involve reading, appraising and looking out for information in publications, the analysis of the philosophical, pedagogical, psychological, scientific and methodological literature devoted to synergy between research and learning, and its significance for Humanities students;

- Regulatory - legal documentation, requirements from the Federal State Educational Standards of Higher Professional Education;

- Internet-resources;

- Studying and generalizing the mass and innovative teaching experience gained by universities;

- Studying teacher's materials, i.e. curricula, textbooks and other teaching materials of traditional and innovative types, as well as those developed by instructors themselves;

- Empirical - seeking and using data and considering them through inductive reasoning i.e. pedagogical observation over educational process, testing teachers and students;

- Pedagogical experiments (ascertaining and developing), monitoring techniques (Portfolio, tests), designing and testing of the cross-disciplinary modules based on the principles of synergy, i.e. students' self-organization, self-transformation, involving content-based, technological, and criteria methods;

- Data processing;

- Delphi technique, or other methods of expert estimation.

\section{Results}

\section{Didactics}

The didactic constituent of the cross-disciplinary educational module is built according to synergetic principles of students' self-organization and selftransformation when they are involved in learning activities. The content of these activities reflects the manner and peculiarities of Humanities and Social Sciences interaction forms to develop willingness of the students for their further self-organization and self-transformation outcomes. It meets such demands as: coordination of basic concepts, self-organization of crossdisciplinary communication, formulating a heuristic hypothesis which is similar to true to life and is focused on transferring didactic elements from one discipline, or course, to another one taking into account the principles of selforganization and self-transformation. The cross-disciplinary content of the module is a complete unit of learning material improved with innovative methods recommended, the knowledge monitoring system allowing fast adjustment of the cross-disciplinary communication in learning. 


\section{Synergy of the cross-disciplinary learning module}

The algorithm of designing and implementing the cross-disciplinary module in Humanities based on synergetic approach may be presented in the following sequence:

- Defining the problem. The core of each module is a relevant problem to deal with: if there is no problem there is no activity. The problem that requires cross-disciplinary knowledge and making solutions creates or improves motivation in creative activities.

- Identifying personal, social, political, cultural and cognitive importance of planned activity results: it may be, for instance, the international draft of the Law On Protection of Historical and Cultural Monuments, Monuments to Great Patriotic War Heroes ( 1941 - 1945) on the territories of various countries; creating a video on the problem studied, and developing proposals for its solution; activities;

- Organizing the students' work in individual form, pair and group

— Distributing the material of the module, i.e. writing a syllabus for a cross-disciplinary module (with enlisting intermediate results);

- Using interactive technologies that involve the following sequence of actions:

1. Defining the goals and objectives of the research through "brainstorming", business games, etc.;

2. Putting forward the hypotheses;

3. Discussing the research methods (the analysis of information, facts, statistical and experimental methods, monitoring, etc.);

4. Discussing the ways of presenting the achieved results (presentation, role play, reports, articles, etc.);

5. Collecting, systematizing and analyzing the data;

6. Summarizing, recording the results and presenting them;

7. Making conclusions, identifying another research problem.

\section{Classification of methods}

Methods for implementing cross-disciplinary modules may be classified on the basis of synergetic approach applied to achieve the goal of cross-disciplinary communication when maintaining Humanities students' self-organization and self-transformation. While carrying out the research we have found that these parameters correspond to the project-based learning, planning through imitation the forthcoming academic and practical activities, constructive learning, roleplaying and business games, performance portfolio, corporative trainings, evolving diagnostics, and a case - study method.

The dominant element in project-based learning techniques is the practical intention that the student works at, to put it into his life and practice. It comprises independent determination of the problem, objectives and tasks; perspective work-plans and their practical implementation, evaluation and quality control of the final product. The product is presented in the form of recommendations for educational institutions, companies and agencies; 
students' supportive notes and the materials on a given topic, articles, essays, etc.

Planning through imitation is to some extent similar to role-playing in learning process. According to research results, this technique proved to stimulate student's individual activity and develop his skills and abilities for team work. At the same time the students understand the interrelation and dependence relationship of the techniques used and the material studied.

Situational technique to stimulate analytical thinking, develop the ability to transfer and put theoretical knowledge of various disciplines into practice.

The interactive techniques based on interaction, interrelation and cooperation. They have multiple benefits as the instructor can easily and quickly assess if students have really mastered the material and decide if he needs to dedicate more time to it, is able to measure student understanding as students may not actually learn the material until asked to make use of it in assessments. Besides, students are revived from their passivity of merely listening or doing routine boring work and become attentive and engaged, and the work is often perceived as "fun," The essence of interaction lies not only in the processes of perception, memory, and attention, but, first of all, in the fact that synergetic principles play a significant role in self-organization, creative and productive thinking, behavior, and communication. The interactive technology allows to interchange the instructor - student roles. Knowledge and information modify their roles, i.e. the role of knowledge translator (the instructor) is substituted by the role of a partner. After being an object, the student becomes a subject of interaction. But knowledge here is not considered as the goal itself but as the means for further actions and activities. The synergy of interactive technologies is also determined by the fact that they ensure transition from the instructordriven learning to the student-driven learning process. In the course of implementing the cross-disciplinary modules in learning we assist in student self-organization through changes in value system, perceiving learning as individual discovery and findings, and the search for personal rethinking and understanding of the information. All the students' learning process appears to be his creative activity with three types of operations: logical, intuitive and heuristic. They are specified by their own features:

- the logical sequence of operations is characterized by a solution algorithm and descriptions, this activity guarantees a result, or success;

- the intuitive sequence is characterized by emotional abilities that may helpful in solving problems, making a scientific forecast and enriching personal experience;

- heuristic sequence of operations is built on intellectual abilities, such as willingness to present, analyze, compare, range, highlight, organize, and make discoveries.

The established operations tested and appraised in the course of the study allowed to classify the interactive techniques (as discussion, role-playing and sensitive training) according to the synergistic factors.

Evolving diagnostics is the technique aimed at developing motivation for professional growth, adequate self-esteem, student's personal and professional status. 
Case-study is a method involving students into solving a true social challenge, or problem, themselves. At the starting point of the learning case study they are which provided with the details about the problem within the subject, or course, frame. They define the problem as clearly as possible, seeing its limits and its implications, assemble and evaluate all available relevant data, using their research and analysis skills, examine potential solutions and their possible consequences, looking at a variety of options. In the long run, they adopt and evaluate a solution, considering its potential effectiveness, which is subjected to an expert review. While analyzing and searching for optimal solution, the students get motivated to achieve goals, develop flexible thinking, corporate attitude, and mutual responsibility. The method is very popular because the process of self-transformation develops naturally.

A performance portfolio is used as an evaluation mechanism for students' personal development and as a factor for designing students' individual training trajectories, systematic and organized evidence gathering that serves a method to reflect on their personal activity and results, or outcomes, presented for current evaluation of the learning success. Within the issue under study, a portfolio is primarily a form that is able to demonstrate continuously forming mechanisms for intellectual self-organization, self-transformation, selfrealization, self-evaluation, and achieving the objectives. It is able to help the observer to determine the particularities of the courses studied and the quality of learning using cross-disciplinary module content, and make further analyses and reflection on the student performance.

\section{Discussions}

The effectiveness of cross-disciplinary learning modules as pedagogical condition of implementing synergetic ideas in developing students' self-organization and self-transformation within Humanities framework is proved by the results of experimental modules introduced into the university curriculum (philosophy, history, pedagogics, literature, etc.). The expert evaluation of the results in performing self-transforming activities by students when studying the modules has appeared to be a concrete evidence of the improved level in crossdisciplinary communication. It is supported by the following indicators: 'Have an idea' - the cross-disciplinary communication has not been developed (35\%); 'Know' - as the ability to reproduce, cross-disciplinary communication has not been developed (43\%); 'Be able' - a sufficient level of cross-disciplinary communication (53\%); 'Have skills' - as the ability to perform in new conditions, demonstrated a high level of cross-disciplinary communication (67\%). The initial level of development ranged from 15-34\%.

\section{Conclusion}

The theoretical and practical importance of the investigated problem is determined by the necessity to introduce synergetic guidelines in Humanities learning at university with the goal of identifying the genuine, intrinsic backgrounds, foundations, and relations between the various elements of the learning process, as well as the intention to create a qualitatively new integral structure. The results of the research reported here let us suggest that, in Humanities, they act as techniques and elements of the learning crossdisciplinary modules. They represent the basic concepts and categories covering the concept of cross-disciplinarily; the principles of self-organization and self- 
transformation as the leading concepts of the synergetic approach, creating syllabus, determining techniques and developing performance criteria, piloting the ideas within every subject of the Humanities curriculum. At every level of implementing the cross-disciplinary educational modules the issues of using synergetic ideas of self-organization and self-transformation and Humanities traditional structure have shown to be reasonable and effective. Se hope that the materials proposed may be helpful for the systems of continuing professional education and retraining of pedagogical resources, young scientists and postgraduates, officials and experts managing and controlling educational process, and, of course, to all those who are interested in successful research work at university and synergy issues being developed incorporated into educational system in Russia.

\section{Disclosure statement}

No potential conflict of interest was reported by the authors.

\section{Notes on contributors}

Tatyana A. Olkhovaya is PhD, Professor of Orenburg State University, Orenburg, Russia.

Alexander E. Shukhman is $\mathrm{PhD}$, Professor of Orenburg State University, Orenburg, Russia.

Victoria V. Nevolina is PhD, Professor of Orenburg State Medical University, Orenburg, Russia.

Lyudmila A. Amirova is PhD, Professor of Bashkir State Pedagogical University named after M. Akmulla, Ufa, Russia.

Natalia A. Zaitseva is PhD, Professor Plekhanov Russian University of Economics, Moscow, Russia.

\section{References}

Boguslavskiy, M. V. (1999) Passion for synergy. World Education, 5, 17-21.

Budanov, V. G. (2009) Methodology for synergy in postnonclassical science and education. Moscow: LKI. 240p.

Erdyneeva, K.G., Nikolaev, E. L., Azanova, A. A., Nurullina, G. N., Bogdanova, V. I., Shaikhlislamov, A. K., Lebedeva, I. V., Khairullina, E. R. (2016) Upgrading Educational Quality through Synergy of Teaching and Research. International Review of Management and Marketing, 6(1), 106-110

Levina, E. Y., Akhmetov, L. G., Latipova, L. N., Mirzagitova, A. L., Mirzanagimova, F. I., Latipov, Z. A. \& Masalimova, A. R. (2015) Diagnostics of Educational Activity Quality on the Basis of Qualitative Methods. Asian Social Science, 11(4), 246-251.

Vyugina, S. V. (2013) Principles Synergetic in the Training of Technical Profile. Bulletin of the Kazan Technological University, 3 (16), 312-314.

Zapesotsky, A. S. (2003) Education: philosophy, culture, politics. Moscow: Science. 456p.

Zeer, E. F. (2009) Psychology of professional education: the textbook for students of higher educational institutions. Moscow: Academia. 240p.

Zimnyaya, I. A. (2003) The key competences - a new paradigm of education result. Higher Education Today, 5, 34-42. 